\title{
Desenvolvimento da criatividade na infância na abordagem histórico-cultural de Vigotski
}

\author{
Development of creativity in childhood in Vigotski's historical-cultural approach
}

\author{
Cleber Melo da Silva'
}

Resumo: Este artigo tem como tema a relação entre o desenvolvimento da criatividade em crianças no contexto escolar e os processos artístico-pedagógicos de criação e imaginação à luz da psicologia históricocultural de Vigotski. A pergunta que norteou nosso estudo foi: Em que medida o desenvolvimento da criatividade, enquanto um processo psicológico, é estimulado por processos de sistematização artísticopedagógicos no contexto escolar? Estabelecemos como objetivos investigar a elaboração teórica de Vigotski acerca do construto da criatividade; identificar nas obras do autor o papel da escolarização no desenvolvimento da criatividade; criar uma proposta de intervenção que estimule o desenvolvimento do construto criatividade mediado por atividades artístico-pedagógicas. A metodologia desenvolvida foi uma pesquisa teórica, de caráter bibliográfico, com uma abordagem qualitativa. A sistematização metodológica foi pautada pelo materialismo histórico e dialético coerente com o autor estudado.

Palavras-chave: Criatividade; Arte; Psicologia educacional.
Abstract: This article has as its theme the relationship between the development of creativity in children in the school context and the artisticpedagogical processes of creation and imagination in the light of Vigotski's historical-cultural psychology. The question that guided our study was:To what extent is the development of creativity, as a psychological process, stimulated by artistic-pedagogical processes in the school context? We set out to investigate the theoretical elaboration of Vigotski about the construct of creativity; to identify in the author's works the role of schooling in the development of creativity; create an intervention proposal that encourages the development of the construct mediated by artisticpedagogical activities. The methodology developed was a theoretical research of bibliographic character with a qualitative approach. The methodological conception was guided by historical and dialectical materialism consistent with the author studied.

Keywords: Creativity; Art; Educational psychology.

\footnotetext{
1 Estudante do Curso de Psicologia da Universidade La Salle - Canoas/RS. Pedagogo formado pela Universidade Federal do Rio de Janeiro (UFRJ) e Professor da Educação Básica da Rede Municipal de Educação de Canoas/RS.

E-mail: cleber.silva0338@unilasalle.edu.br
} 


\section{Introdução}

Não é raro encontrarmos o termo criatividade associado às possibilidades de inserção no mercado de trabalho na contemporaneidade. Cada vez mais a sociedade vem discutindo a criatividade como um atributo pessoal que pode impulsionar e ser decisivo na empregabilidade dos sujeitos, delegando a estes, a responsabilidade pela sua alocação no mundo do trabalho. Diferentemente de décadas passadas onde as relações de trabalho e renda, na sociedade fordista, eram marcadas pela reprodução rígida da cultura de classes, do corpo domesticado e do sistema de trabalho. Hoje, há uma diversidade nas relações econômicas na sociedade contemporânea, caracterizada pela flexibilidade, emergência de novas formas de consumo, nichos e especializações técnicas e tecnológicas. Por tudo isso, precisamos retomar a perspectiva vigotskiana de que as relações humanas com o mundo não são relações diretas, mas relações profundamente mediadas, cujos efeitos atingem dimensões psicológicas. O núcleo da abordagem deVigotski (2001) está no fato do que aparece como individual, como os nossos pensamentos, emoções, afetos, fantasias, vontades e a nossa memória terem no fundo uma base sociocultural. Nesse aspecto, precisamos criar cenas pedagógicas provocativas à interação, à sensibilidade e à expressividade humana por meio de estratégias e ferramentas voltadas à criatividade. 0 contexto contemporâneo suscita a necessidade de novas competências como exercício criativo na escola, entre elas a flexibilidade, trabalho em grupo, adequação às novas linguagens e desenhos tecnológicos dos mercados e da condição humana genuinamente imaginativa (Kober, 2004; Habowski, \& Conte, 2019).

Geralmente, conforme Kober (2004), as mudanças econômicas e sociais têm repercussões no sistema escolar. Escolas de empreendedorismo, economia criativa, programas e propostas educacionais ativas voltadas às competências, entre outras, vêm ganhando cada vez mais espaço no cenário educacional. Inclusive, materializando-se no currículo escolar e interferindo nos processos de contextualização do conhecimento, que "implica reconhecer o potencial recriador dos sujeitos" (Habowski, \& Conte, 2020, p. 1). Um exemplo disso é a Base Nacional Comum Curricular (BNCC), documento legal de organização curricular publicado em 2017, cuja criatividade tem papel de destaque no documento legal, seja através da sua presença em al gumas áreas do conhecimento, seja através das habilidades e competências ou como um dos objetivos da educação básica (Brasil, 2017). A criatividade volta ao auge nos debates acadêmicos envolvendo profissionais da educação, instituições universitárias, sociedade civil organizada e profissionais interessados no desenvolvimento humano, tais como psicólogos e pedagogos, por exemplo. Cabe ressaltar que a valorização da criatividade no contexto econômico e social, diferentemente da educação, parece estar mais associada a uma ideia de atributos comportamentais ou competências do que a um processo psicológico passível de desenvolvimento humano, o que não inviabiliza o estudo desse tema, pelo contrário, o torna mais complexo e necessário. A partir desse contexto social que reforça a hipótese de que a arte não está separada da vida, expandindo a perspectiva médica do cuidado para o crescimento infantil, torna-se instigante estudar a criatividade e seu desenvolvimento em crianças no contexto escolar.

Este artigo tem como tema a relação entre o desenvolvimento da criatividade em crianças no contexto escolar e os processos de sistematização artístico-pedagógicos de criação e imaginação à luz da psicologia histórico-cultural de Vigotski. Entendemos que as dimensões artístico-pedagógicas são compostas por um conjunto de ações didáticas justificadas nas linguagens artísticas e interdisciplinares marcadas pelo ver (apreciação perceptiva), fazer arte e contextualizar (analisar), como o teatro e a dança, por exemplo. Além disso, são formas de comunicação dotadas de bases científicas, sendo produzidas num contexto histórico e cultural, para dar vazão às emoções como possibilidades criativas, lúdicas, imaginativas e estéticas (Marques, 2012).

Nessa visão de abertura às linguagens relacionais da arte, lançamos a seguinte problemática: Em que medida o desenvolvimento da criatividade, enquanto um processo psicológico, é estimulado por processos artístico-pedagógicos no contexto escolar? Além do nosso interesse pela área da psicologia educacional, nosso tema e problema de pesquisa surgiram a partir da disciplina de Psicologia Infantil I ofertada no segundo semestre do ano de 2020, no Curso de Psicologia da Universidade La Salle, de Canoas/RS, também compartilhada com os colegas do Curso de Pedagogia, da referida instituição. Durante a disciplina, fomos estimulados a pensar, através das aulas, fazer leituras e a produção de um trabalho final sobre o desenvolvimento da infância, a partir de diferentes abordagens teóricas, entre elas, a Psicologia Histórico-Cultural de Vigotski ou Psicologia Sócio-Histórica. Os estudos, bem como o olhar pedagógico dos demais estudantes da área da educação, nos estimularam a refletir sobre 0 desenvolvimento da criança em um dos espaços privilegiados da interação e prática social: a escola. Esse percurso nos levou a pensar na escolarização como um espaço de desenvolvimento psicológico das crianças, em especial dos seus processos psicológicos básicos, entre eles, a criatividade.

A partir dos interesses suscitados na disciplina de Psicologia Infantil I, estabelecemos como objetivos investigar a elaboração teórica de Vigotski acerca do construto da criatividade; identificar nas obras do autor o papel da escolarização no desenvolvimento da criatividade; criar uma proposta de sistematização e intervenção que estimule o desenvolvimento da abordagem criativa mediada por atividades artístico-pedagógicas (Habowski, \& Conte, 2019, Habowski, \& Conte, 2020). O referencial teórico utilizado para dar conta dos objetivos propostos foi Vigotski (2001, 2008, 2010, 2014), que aborda 0 tema investigado, nos seguintes elementos: Psicologia da Arte, Imaginação e Criatividade na Infância, Psicologia Pedagógica (A educação estética) e Brincadeira e seu papel no desenvolvimento psíquico da criança.

\section{Método}

0 trabalho elaborado e aqui descrito foi o resultado das atividades avaliativas e das tensões entre imagens do pensamento e conceitos para o desenvolvimento de uma nova proposição de sentido, da metáfora para a realidade, da disciplina de Psicologia da Infância I do Curso de Psicologia da Universidade La Salle, em Canoas/RS. Instigados a propor uma intervenção com crianças, tendo por base os teóricos clássicos do desenvolvimento infantil e suas respectivas abordagens, resolvemos organizar uma pesquisa teórica justificada em uma proposta de intervenção. Cabe ressaltar que a disciplina não propôs a realização prática de uma intervenção, o que, se fosse o caso, resultaria em uma pesquisa-ação, do tipo intervenção pedagógica, conforme Damiani (2013). Logo, definimos uma pesquisa teórica acerca do problema empírico abordado para garantir a exequibilidade em um tempo relativamente curto, como é o tempo de uma disciplina semestral de curso de graduação. Essa pesquisa se insere em uma abordagem qualitativa (Minayo, 2001) e tem caráter bibliográfico (Severino, 2010), com foco na revisão de literatura e análise de fontes bibliográficas primárias a respeito do desenvolvimento da criatividade em Vigotski e suas implicações pedagógicas.

A pesquisa bibliográfica é aquela que se realiza a partir do registro disponível, decorrentes de pesquisas anteriores, em documentos impressos, como livros, artigos, teses, etc. Utiliza-se de dados ou 
de categorias teóricas já trabalhadas por outros pesquisadores e devidamente registrados. Os textos tornam-se fontes dos temas a serem pesquisados. 0 pesquisador trabalha a partir das contribuições dos autores dos estudos analíticos constantes dos textos. Severino $(2010$, p.122).

Para a investigação teórica foi feito um levantamento bibliográfico acerca do tema de pesquisa, em especial as contribuições de Vigotski sobre a criatividade, a criatividade na infância e suas repercussões psicopedagógicas. Para a formulação de ações artístico-pedagógicas que estivessem associadas ao desenvolvimento da criatividade, realizamos um levantamento de questões e problemas já postos anteriormente no campo da arte-educação, especialmente em teatro e dança. Em vista deste contexto, realizamos um recorte que fosse adequado ao tempo disponível para a sistemática da disciplina e que fosse fidedigno aos principais teóricos relacionados aos temas investigados (criando uma diferença e ao mesmo tempo um vínculo, uma relação entre os pensadores). Em relação ao construto da criatividade, nosso recorte deu enfoque às produções de Vigotski sobre a criatividade, presente nas seguintes obras: Psicologia da Arte, Imaginação e Criatividade na Infância e A educação estética. 0 último compreende o capítulo XIII, da obra Psicologia Pedagógica. Acerca da questão e proposição artístico-pedagógica associada à criatividade, nosso recorte deu ênfase às seguintes obras: Jogos teatrais na sala de aula, de Viola Spolin (2015); Teatro e Dança nos anos iniciais, de Ferreira e Falkembach (2012) e Dançando na Escola, de Marques (2012).

0 tratamento dos dados obtidos através da pesquisa bibliográfica foi feito a partir de uma análise de conteúdo. Para Severino (2010), a análise de conteúdo é uma metodologia de tratamento dispensada às informações obtidas no processo de coleta de dados. Trata-se, então, de compreender de forma crítica o sentido manifesto ou ocul to das representações estudadas. Aqui, nossa análise de conteúdo deteve-se em capturar a essência do fenômeno pesquisado (o potencial da arte para um novo tipo de aprendizagem), de acordo com a teoria histórico-cultural (Vigotski, 2001), e compreender as suas implicações para o desenvolvimento da criança, bem como suas repercussões pedagógicas, devido ao fato da escola - espaço pedagógico por excelência - ser o local privilegiado para a interação e o desenvolvimento das crianças.

Nosso trabalho se inscreve na concepção metodológica do materialismo histórico e dialético que pressupõe, além da interpretação crítica dos dados, a compreensão dialética de que a arte visualiza e materializa a capacidade humana de ultrapassar limites fixados, de deixar contextos estereotipados, a capacidade de criar novos contextos, com a possibilidade de olhar o contraditório. Nesse caso, a análise é capaz de compreender a essência do fenômeno para além da aparência, a partir da articulação entre os fundamentos teóricos da psicologia histórico-cultural e a natureza da arte que faz com que os sentimentos se transformem e possam reagir, avançar para uma aprendizagem expansiva. Em relação ao binômio aparência-essência dos fenômenos pesquisados, Netto (2011) e Kosik (1969) nos ajudam a compreender que a concepção materialista e dialética deve nos conduzir, a partir da realidade concreta e imediata, superficial, para um entendimento da dinâmica e estrutura do objeto investigado. Porém, compreender a essência do fenômeno analisado possibilita não apenas a interpretação da realidade, mas nos permite também conhecer a estrutura e a dinâmica do fenômeno analisado, desenvolvendo os significados objetivos, os sentidos pessoais e as ferramentas que apoiem na transformação da realidade. É exatamente essa concepção que nos permitiu, a partir dos estudos realizados, propor uma intervenção que possa ser significativa e transformadora no cenário do desenvolvimento da criatividade enquanto uma função psicológica indispensável à vida em sociedade.

Como procedimento de síntese, para atender ao objetivo da disciplina de Psicologia Infantil I, de organizar uma proposta de intervenção nas abordagens do desenvolvimento infantil, que nós resolvemos construí-la mediada pela arte-educação, decidimos relacionar os aspectos centrais das contribuições deVigotski - a respeito do desenvolvimento da criatividade e suas implicações pedagógicas - com as proposições didático-pedagógicas, especialmente 0 teatro e educação, dos autores referenciados para essas áreas.

\section{Discussão}

Vigotski (2014) chama de criatividade a atividade humana capaz de criar algo novo, seja ela uma representação objetiva, uma construção mental ou uma emoção típica do ser humano. Para o autor, é possível distinguir dois tipos básicos de criatividade: reprodutivo e imaginação criativa. A atividade reprodutiva está fortemente ligada à memória e sua característica consiste em reproduzir ou repetir comportamentos, ações e atitudes anteriormente elaboradas. Nesse tipo básico, não se cria algo novo em si, apenas repete-se em menor ou maior grau alguma atitude ou ação importante para solucionar ou resolver al guma questão prática.

Vigotski (2014) destaca a importância dessa criatividade reprodutiva, pois nos permite conservar experiências anteriores fundamentais para a espécie humana, tanto em sentido adaptativo/biológico quanto social (da tradição cultural de experiências). Esse atributo facilita a nossa análise criativa pelo exercício da comunicação e adequação ao meio externo e nos estimula a repetir hábitos para solucionar questões semelhantes, qualificando os recursos diversos. 0 autor bielorruso destaca ainda que essa função reprodutiva da criatividade está relacionada à memória tendo como substrato fisiológico a plasticidade do nosso sistema nervoso, que permite ao cérebro preservar as experiências vividas e facilitar a sua repetição. De acordo com Vigotski (2014), se a atividade cerebral se restringisse apenas à reprodução e conservação de experiências passadas, nossa capacidade de adaptação e desenvolvimento seria restrita às condições preexistentes.

Toda a atividade humana que não se restringe à reprodução de fatos e impressões vividas, mas que cria novas imagens e ações, pertence a essa segunda função criadora e combinatória. 0 cérebro não é apenas o órgão que se limita a conservar ou reproduzir nossas experiências passadas, mas é também um órgão combinatório, criador, capaz de reelaborar e criar, a partir de elementos de experiências passadas, novos princípios e abordagens [...]. É justamente a atividade criadora humana que faz do homem um ser que se projeta para o futuro, um ser que cria e modifica o seu presente. (Vigotski, 2014, p.3).

Na visão de Vigotski (2014), a criatividade é um processo mental que se alimenta da realidade e a transforma. As ações humanas se baseiam na modificação permanente das condições da natureza, por isso, a centralidade da imaginação e da criatividade como uma função importante para a vida. Não é um talento natural, mas uma necessidade. 0 autor acrescenta, 
A psicologia chama de imaginação ou fantasia essa atividade criadora do cérebro humano baseada nas capacidades combinatórias, atribuindo a elas um sentido diferente daquele que Ihe é atribuído cientificamente [...]. Nesse sentido, absolutamente tudo o que nos rodeia e que foi criado pela mão do homem, todo o universo cultural, ao contrário do universo natural, é produto da imaginação e criação humanas. (Vigotski, 2014, p.4).

Sendo assim, o ser humano não apenas tem a capacidade de reproduzir, mas de combinar, recriar e dar significado (por signos) para aquilo que está disponível a sua volta. A imaginação e a fantasia são condições que socialmente se desenvolvem e que permitem ao ser humano criar, modificar, ressignificar e se adaptar aos diferentes contextos que se apresentam. Partindo dessa caracterização sobre a imaginação e a criação, 0 autor afirma:

Se compreendermos a criatividade desse modo, então é fácil notar que os processos criativos se observam em toda a sua intensidade já na infância precoce. Uma das questões mais importantes da psicologia e da pedagogia infantil é a capacidade de criação nas crianças, do estímulo dessa capacidade e a sua importância para o desenvolvimento geral e a maturação da criança. (Vigotski, 2014, p.6).

Daí que a capacidade de imaginação na infância está demonstrada nos processos de criação literária, de criação teatral, do desenho, do jogo ou das linguagens que surgem das brincadeiras. Tais processos são muito comuns na criança, especialmente em idade escolar.

Os jogos geralmente são apenas reflexos daquilo que a criança viu e ouviu dos mais velhos, no entanto, esses elementos da experiência alheia nunca se reproduzem na brincadeira do mesmo modo como se apresentaram na realidade. Os jogos da criança não são uma simples recordação de experiências vividas, mas uma reelaboração criativa dessas experiências, combinando-as e construindo novas realidades segundo seus interesses e necessidades. A vontade das crianças de fantasiar as coisas é resultado da sua atividade imaginativa, tal como acontece na sua atividade lúdica. (Vigotski, 2014, p.6).

A atividade lúdica da criança enquanto dimensão estética que desperta a imaginação e o pertencimento tem um papel fundamental na preparação para o desenvolvimento do pensamento na criança. 0 jogo, para 0 autor, é a primeira atividade em que a imaginação criativa surge orientada pela percepção, memória e pensamento visual. Na visão de cada criança está a imaginação criadora relacionada às reelaborações de jogos que as crianças fazem nas experiências vividas no seu ambiente. Éuma forma de se apropriar do mundo circundante, pelo ol har atento e experiências, para se deixar interrogar pela arte e aguçar a criatividade.

Na pesquisa sobre A brincadeira e o seu papel no desenvolvimento psíquico da criança, Vigotski (2008) relaciona a brincadeira a importantes processos nas crianças, entre eles 0 afeto, o pensamento abstrato, salto no desenvolvimento, suporte material para a imaginação, predomínio do sentido sobre o objeto, regras explícitas ou implícitas, criação de situações imaginárias e a realização de desejos. A brincadeira, por suas características, se assemelha a outro processo destacado porVigotski: a criatividade teatral na infância. Para o autor, a criatividade teatral é um dos gêneros mais frequente e comum nas criações artísticas das linguagens expressivas da infância, pois o cenário do teatro nos apresenta o desenrolar da vida desde a infância.

E pode-se compreender e explicar por que essa forma agrada mais às crianças por dois aspectos fundamentais: em primeiro lugar porque 0 drama se baseia nas ações e em fatos que são obras da própria criança e, desse modo, relaciona de modo imediato, eficaz e direto a criação artística com as experiências vividas pela criança. (Vigotski, 2014, p.87).

É na forma dramática que o ciclo completo da imaginação se realiza. As imagens criadas a partir de elementos da realidade concretizam-se e materializam-se novamente na realidade. Seguindo o raciocínio do autor,"0 anseio para a ação, representação e concretização, que está presente no próprio processo da imaginação, encontra-se aqui realizado plenamente" (Vigotski, 2014, p. 88). Sobre 0 teatro infantil, Vigotski (2014) destaca algumas diferenças em relação ao teatro adulto, enquanto linguagem técnica, que devemos considerar. 0 teatro é composto por: a) significado - individual e com valor para o desenvolvimento das crianças; b) realidade - emancipação do real para as crianças; c) técnica - secundária às crianças, nos importa a brincadeira; d) objetivo - meio de desenvolvimento do pensamento abstrato e controle da vontade às crianças; e) produto - importa-nos o processo de criação e não o produto artístico final. Inclusive, para 0 autor, os aspectos técnicos da linguagem teatral (figurinos, cenários, etc.) estimulam a criatividade e a imaginação das crianças, transformando tais aspectos técnicos em outros significados, como parte de um todo que as crianças têm interesse. Ou seja, envolver-se na construção de cenários e figurinos têm valor semelhante aos elementos dramáticos da brincadeira e das ações dos personagens. Assim como a criatividade artística está presente na infância, seja através da brincadeira, do jogo dramático infantil, do desenho na infância, da criação literária, ela também está presente na criação artística enquanto uma prática social. Compreender a arte como prática sociocultural nos ajuda a entender o papel do ensino da arte e sua constituição enquanto prática de experimentação nos currículos escolares, e como ela se relaciona com o desenvolvimento cultural das crianças e adolescentes, em termos de desenvolvimento da criatividade.

Ao introduzir o tema da arte no contexto social, em Psicologia da Arte, Vigotski (2001) destaca que os elementos imaginativos se apresentam como fenômeno humano e social, que se origina da relação do homem com o meio físico, social e cultural. Apesar da reação artística ser registrada em cada sujeito de forma unilateral, a arte é social entre as pessoas, pois diz respeito às relações de reciprocidade entre elas e as representações que fazem do mundo e de si mesmas. Para Vigotski (2001, p.12), a arte ganha relevância na medida em que "tudo consiste em que a arte sistematiza um campo inteiramente específico do psiquismo do homem social - precisamente o campo do seu sentimento", ou seja, uma nomeada técnica social do sentimento. De acordo com o exposto, a arte conjuga diversos elementos que unem imagens a conceitos, dentre outros, destacamos dois aqui: o primeiro por ser uma atividade humana de criação, imaginação e fantasia que emerge, por formas indiretas, do contexto real; o segundo elemento por ser uma prática humana relacionada a expressão, comunicação e vazão do sentimento através de uma técnica socialmente desenvolvida. 0 estudo 
de Vigotski (2001) sobre a arte representa, também, grande relevância para a educação pois conjuga aspectos ligados a desenvolvimento cognitivo, afetivo e social trazendo à reflexão a capacidade criativa e imaginativa presente na infância, bem como a importância dessas funções mentais para o desenvolvimento global e integral ao longo da vida.

Em Psicologia Pedagógica, especialmente no capítulo XIII, é abordada a educação estética, momento em que Vigotski (2010) sintetiza alguns aspectos fundamentais sobre as implicações pedagógicas das suas elaborações no campo da arte. Um leitor menos assíduo de Lev Semenovich Vigotski (1896-1934) talvez não esteja acostumado com a maneira pela qual o autor postula suas elaborações. Parte-se de uma contextualização crítica das elaborações teóricas já formuladas por outras abordagens sobre o tema que vai argumentar, disseca pontos positivos e negativos e apresenta uma elaboração original sobre o tema em questão. Não foi diferente sobre a relação e os processos de transformação da arte e da educação. Vigotski (2010) apresenta três negativas sobre o pensamento vigente no início do século XX, a saber: a) a arte não é fonte de ensinamento moral, pois o adulto não tem controle sobre o efeito moral da obra e a ênfase no valor moral se torna obstáculo à apreensão do valor estético; b) a arte não é fonte de conhecimento, pois a arte não reflete a realidade plenamente, logo, não podemos conhecer uma realidade a partir da sua arte, pois a arte transfigura a realidade; c) a arte não é fonte de prazer, pois provoca no sujeito um pensamento complexo e uma intensa atividade psíquica que exige esforço daquele que a usufrui.

A partir das negativas, Vigotski (2010) elenca três âmbitos da relação da arte com a educação. 0 primeiro diz respeito à criação infantil, reconhecendo nesse âmbito alguns pilares: a arte na escola tem o papel de ensinar a criança a criar; o valor pedagógico é maior do que o valor estético; manifestação livre da brincadeira e do jogo; a criação é transitória e nunca definitiva; necessária à criança por estimular suas expressões e provocar deslocamentos de seu sentido. 0 segundo âmbito, de acordo com Vigotski (2010), é o ensino profissional da arte: talento como resultado da educação; oposição à ideia de dom ou de natureza mística; 0 ensino técnico da arte deve integrar o sistema educacional; ensinar a criar e a perceber a arte. Já o terceiro âmbito diz respeito ao juízo estético. Perceber a arte, vivenciar a arte, conviver com a arte tem a ver com a sociabilidade e a acessibilidade do processo expansivo, tanto interno quanto externo, tanto objetivo quanto subjetivo, tanto individual quanto social. Por tudo isso, a percepção artística se aproxima de uma intensa atividade psíquica. 0 autor insiste na importância de introduzir a vivência estética na própria vida ativa, como uma forma de aprendizagem. "A poesia não está apenas onde existem grandes criações artísticas, mas em todos os lugares onde a palavra humana estiver. E essa poesia de cada instante é o que talvez constitua o objetivo mais importante da educação estética" (Vigotski, 2010, p. 352).

A partir do exposto, para darmos conta das contribuições psicológicas de Vigotski justificadas na perspectiva Histórico-Cultural, surgiu a necessidade de produzir uma proposta que abordasse a percepção e os modos de ver o mundo na relação didático-pedagógica, para a prática artística com crianças. Em relação às atividades artístico-pedagógicas, o referencial teórico para abordar o fenômeno do desenvolvimento da criatividade, a partir das artes da cena, estabelecemos uma proposta de sistematização com as contribuições de Ferreira (2016), Ferreira eFalkembach (2014), Marques (2012) e Spolin (2015). Éna escola que acontece 0 encontro sistematizado entre a arte e a criança. Apesar do desenvolvimento desigual, no Brasil, entre as linguagens artísticas no ambiente escolar - sejam nos aspectos históricos ou didáticos - a dança, o teatro, a música e as artes visuais vêm ganhando maior viabilidade no contexto escolar, especialmente no plano legal, através dos Parâmetros Curriculares Nacionais (Marques, 2012) e, recentemente, da Base Nacional Comum Curricular (Brasil, 2017). 0 trabalho com o corpo enquanto potencial criativo e imaginativo observado desde a infância, principalmente através da brincadeira e do jogo, nos leva a uma importante consideração a respeito da relação entre o teatro e a dança enquanto linguagens da cena.

Ainda que a dança e o teatro sejam linguagens artísticas diferentes, comungam de muitos traços, desde seu suposto surgimento e criação nos idos pré-históricos até a natureza psicofísica do trabalho dos atores-bailarinos e da copresença física entre atores-bailarinos e espectadores necessária aos acontecimentos cênicos nas duas linguagens artísticas. (Ferreira, 2016, p.11).

0 encontro entre dança e teatro não é apenas temporal, algo que surgiu na antiguidade e responde ao reencontro no contemporâneo, mas consiste no seu processo de criação e composição, bem como na linguagem estabelecida entre si e o mundo, inclusive a sua compreensão como metáfora. Ferreira (2016), ao estruturar essa reflexão, retoma um importante conceito no campo das artes da cena viva ou artes cênicas (compostas pela dança, o teatro, o circo, a ópera e a performance). Nesse contexto de discussão, a dança e o teatro conservam aspectos técnicos e próprios significativos, com funções estéticas particulares e que nosso propósito de desenvolver uma proposta de intervenção artístico-pedagógica foi demarcada, como abertura e potencial da multiplicidade de suas possíveis aplicações. Contudo, o aspecto técnico tem relevância menor quando propomos trabalhar teatro ou dança com crianças, observando a capacidade de mover-se em contextos formais e de força metafórica que cria uma referência peculiar com o mundo para provocar a diferença. Vigotski (2014), a o falar sobre a criação teatral na infância, adverte que a lei básica da criatividade infantil se encontra no processo criativo, na brincadeira, no jogo, na preparação, e não no resultado, no produto final ou na peça. Nesse sentido, a refletirmos sobre a dança e o teatro com crianças nos interessou, neste percurso de elaboração intencional de uma intervenção, o processo criativo, o envolvimento das crianças, a criação do figurino, do cenário, a elaboração coletiva e individual, a criação coreográfica das próprias crianças, e não o produto final ou a coreografia final (mesmo que aspectos técnicos sejam trabalhados, apreendidos e executados).

Logo, estruturamos a proposta de intervenção, a partir de uma Oficina de Jogos Teatrais na Sala de Aula, de acordo com as proposições de Spolin (2015) e outras experimentações para o processo de compreensão (Tarrago, Habowski, \& Conte, 2017). As categorias planejadas foram os jogos dramáticos, os jogos teatrais e as improvisações. As três práticas funcionando como estímulo para os processos criativos, ora como estímulos estruturados (jogos teatrais), ora como estímulos mais fluídos (jogos dramáticos e improvisação), fazendo do encontro teatral o espaço privilegiado para a emergência da criatividade e a observação da manifestação desse fenômeno, considerando a criatividade como um processo psicológico passível de desenvolvimento na relação intra e interpsíquica.

\section{Considerações}

Compreender as contribuições de Vigotski acerca da criatividade e as suas implicações para o desenvolvimento psicológico da criança, tendo na escola um dos espaços privilegiados para esse processo, foi um desafio. Primeiramente pela exigência de uma leitura atenta de um autor importante para a psicologia do de- 
senvolvimento humano e da aprendizagem, cujas elaborações contemplam tanto o rigor metodológico de uma investigação científica, quanto pela complexidade do seu pensamento em forma de comunicação científica. Criar uma proposta de intervenção com crianças embasada em ações relacionadas em um autor da psicologia do desenvolvimento que defende que o único bom ensino é o que se adianta ao desenvolvimento (Vigotski, 2014) e da aprendizagem convergiu para as seguintes dinâmicas da atividade estético-expressiva e sociabilidade humana. Cabe lembrar que a pedra angular do trabalho de Vigotski (2014) está em nos mostrar que todas as funções do desenvolvimento da criança aparecem em dois planos. 0 primeiro engloba o plano social (entre as pessoas, interpsicológico) e depois o plano psicológico (no interior da criança, intrapsicológico). Sendo assim, sistematizamos nosso projeto de intervenção em uma oficina com três jogos: um jogo dramático, um jogo teatral e uma improvisação. 0 primeiro tem um caráter livre, com alguns poucos estímulos para que as crianças possam trabalhar de forma mais livre a imaginação, se aproximando ao máximo de uma brincadeira de faz-de-conta. Tal dinâmica tem o objetivo de propiciar um espaço de relação entre os participantes como forma de troca de sentimentos, histórias e criatividade. 0 jogo teatral, por sua vez, tem uma estrutura prévia, onde os participantes têm um conjunto de regras e combinações para seguir, e é a partir delas que a criação se estabelece. Exige-se, nesse jogo, a parceria e uma criação em conjunto com quem está na cena do jogo. As ações são sempre endereçadas aos outros, na busca permanente por uma relação que sustente a cena e a criação coletiva a partir de regras estabelecidas. Por fim, a improvisação é um estágio posterior ao jogo teatral, pois os estímulos vão se alterando no decorrer do jogo. Elementos aleatórios podem entrar na cena e devem ser encarados pelos participantes como algo interligado na história que está sendo contada. Tal dinâmica requer e estimula importantes capacidades cognitivas, como a flexibilidade, a resolução de problemas, o raciocínio lógico e a criatividade. A busca por uma proposta de intervenção coerente e fidedigna aos principais pilares do construto da criatividade, à luz da Psicologia Histórico-Cultural, foi um exercício de enorme aprendizado para a nossa formação acadêmica e profissional. A criatividade, geralmente compreendida como um processo psicológico básico, relacionado à inteligência ea resolução de problemas, ganhou novos significados com aspectos relativos à vida prática e cotidiana, da interação, da criação, da originalidade e da genialidade.

Obviamente, os processos de imaginação e criatividade estão presentes em tudo o que a sociedade construiu na sua existência, desde a pequena alteração de um aspecto natural em benefício do ser humano até as grandiosas e complexas criações produzidas pela humanidade. A criatividade não é restrita a um pequeno número de pessoas, fazendo destes, gênios. Eles existem. Vigotski os reconhece. Contudo, 0 autor nos convida a compreender a criatividade como um processo mental presente em todos os seres humanos. A criatividade é um instrumento do qual dispomos para simbolizar o meio, para expressarmos nossas emoções e para nos adaptarmos a novos desafios. Essa capacidade criativa se desenvolve na nossa relação com o meio e com nossos pares como uma forma de compreender a realidade e implica relações, corporeidades, colaboração social e cultural, bem como o reconhecimento aos diferentes ritmos e formas de ver, ler e aprender 0 mundo com o outro. A imaginação criadora gera processos que nos permitem criar e combinar elementos, gerando novas produções materiais, imateriais e/ou culturais. Se essa capacidade de combinar e criar é o mecanismo elementar do processo pelo qual nos apropriamos da experiência humana da história social, então, é consequência direta observar que ela se manifesta durante toda a vida. A infância é uma das fases onde a criatividade começa a se manifestar e das formas mais variadas. A dramatização, a brincadeira, o faz-de-conta, a criação literária e verbal e o desenho são formas de criação e combinação dos elementos experienciados pela criança no seu meio. A criação infantil é uma transfiguração da realidade, é uma releitura particular da criança sobre os fenômenos vividos. É exatamente esse o ponto de ligação entre a arte como prática social e a criação infantil como possibilidade de desenvolvimento, ou seja, é a forma de combinar elementos e criar algo novo.

Logo, pensar o desenvolvimento da criatividade infantil é, também, pensar o desenvolvimento infantil no universo das relações escolares, num ambiente adequado para o desenvolvimento psicológico das crianças, tanto do ponto de vista cognitivo quanto do ponto de vista emocional e sociocultural. A arte enquanto linguagem criativa é fundamental ao desenvolvimento psíquico e interdependente das aprendizagens sociais, pois representa os elos entre a emoção e a cognição, mediados pelo meio social. Em última instância, nos parece essencial pensar a psicologia educacional como a área que mobiliza a relação emoção-cognição-social, tendo a arte como forma superior de desenvolvimento dos sujeitos que dão vida aos processos de ensino e de aprendizagem (capacidades cognitivas e metacognitivas) para as leituras de mundos.

\section{Referências}

Brasil. (2017). Ministério da Educação. Base Nacional Comum Curricular. Brasilia: MEC.

Damiani, M. F. et al. (2013). Discutindo pesquisas do tipo intervenção pedagógica. Cadernos de Educação, Pelotas, 45, 57-67, may/aug.

Ferreira, T., \& Falkembach, M. F. (2012). Teatro e Dança nos anos iniciais. Porto Alegre: Mediação.

Ferreira, T., \& Oliveira, M. (2016). Artes cênicas: teoria e prática no Ensino Fundamental e Médio. Porto Alegre: Mediação.

Habowski, A. C., \& Conte, E. (2019). As tecnologias digitais e o desenvolvimento da criatividade humana em questão. Revista Temas Em Educação, 28(3). https://doi.org/10.22478/ufpb.2359-7003.2019v28n3.46740

Habowski, A. C., \& Conte, E. (2020). 0 ócio criativo e suas perspectivas na educação. Linhas Críticas, 26, 1-17. https://doi.org/10.26512/ Ic.v26.2020.24711

Kober, C. (2004). Educação, trabalho e qualificação profissional. Campinas (SP): Autores Associados.

Kosik, K. (1969). Dialética do Concreto. Trad. Célia Neves e Alderico Toríbio. Rio de Janeiro: Paz e Terra.

Marques, I. (2012). Dançando na Escola. São Paulo: Cortez.

Minayo, M. C. S. (org.) (2001). Pesquisa Social: Teoria, Método e criatividade. 18. ed. Petrópolis, RJ: Vozes.

Paulo Netto, J. (2011). Introdução ao estudo do método de Marx. São Paulo: Expressão Popular.

Severino, A. (2010). Metodologia do trabalho científico. São Paulo: Cortez.

Spolin, V. (2015). Jogos teatrais na sala de aula. São Paulo: Perspectiva.

Tarrago, L. S., Habowski, A. C., \& Conte, E. (2017). A inclusão social por meio das artes: possibilidades e limites na educação. Gestão Universitária, 1, 1-15. http://www.gestaouniversitaria.com.br/artigos/a-inclusa0-social-por-meio-das-artes-possibilidades-e-limites-na-educacao

Vigotski, L. S. (2014). Imaginação e criatividade na infância. Trad. João Pedro Fróis. São Paulo: Editora Martins Fontes.

Vigotski, L. S. (2010). Psicologia Pedagógica. Trad. Paulo Bezerra. São Paulo: Martins Fontes.

Vigotski, L. S. (2008). A brincadeira e o seu papel no desenvolvimento psíquico da criança. Revista Virtual de Gestão de Iniciativas Sociais, 26-36.

Vigotski, L. S. (2001). Psicologia da Arte. Trad. Paulo Bezerra. São Paulo: Martins Fontes. 